\title{
REVIEW
}

\section{The emerging role of FOXO transcription factors in pancreatic $\beta$ cells}

\author{
Dominique A Glauser and Werner Schlegel \\ Fondation pour Recherches Médicales, University of Geneva, Av. de la Roseraie 64, 1211 Geneva, Switzerland \\ (Requests for offprints should be addressed to W Schlegel; Email: werner.schlegel@medecine.unige.ch)
}

\begin{abstract}
FOXO transcription factors critically control fundamental cellular processes, including metabolism, cell differentiation, cell cycle arrest, DNA repair, and other reactions to cellular stress. FOXO factors sense the balance between stimuli promoting growth and differentiation versus stress stimuli signaling damage. Integrated through the FOXO system, these divergent stimuli decide on cell fate, a choice between proliferation, differentiation, or apoptosis. In pancreatic $\beta$ cells, most recent evidence highlights complex FOXOdependent responses to glucose, insulin, or other growth factors, which include regulatory feedback. In the short term, FOXO-dependent mechanisms help $\beta$ cells to accomplish their endocrine function, and may increase their resistance to oxidative stress due to transient hyperglycemia. In the long term, FOXO-dependent responses lead to the adaptation of $\beta$
\end{abstract}

cell mass, conditioning the future ability of the organism to produce insulin and cope with changes in fuel abundance. FOXO emerges as a key factor for the maintenance of a functional endocrine pancreas and represents an interesting element in the development of therapeutic approaches to treat diabetes. This review on the role of FOXO transcription factors in pancreatic $\beta$ cells has three parts. In Part I, FOXO transcription factors will be presented in general: structure, molecular mechanisms of regulation, cellular functions, and physiological roles. Part II will focus on specific data about FOXO factors in pancreatic $\beta$ cells. Lastly in Part III, it will be attempted to combine general and $\beta$ cell-specific knowledge with the aim to envisage globally the role of FOXO factors in $\beta$ cell-linked physiology and disease.

Journal of Endocrinology (2007) 193, 195-207

\section{Part I: introduction to FOXO transcription factors}

\section{Classification and structure of FOXO proteins}

FOXO transcription factors form a subclass of the large family of Forkhead proteins characterized by the presence of a 'winged-helix' DNA-binding domain called Forkhead box, which gave the name FOX proteins to the family (Kaestner et al. 2000). FOXO proteins are conserved from worm to human. While only one FOXO species is known in invertebrates (called dauer formation-16 (DAF-16) in Caenorhabditis elegans and dFOXO in Drosophila), four FOXO species, encoded by four distinct genes, have been identified in mammals: FOXO1 (previously known as FKHR), FOXO3 (previously known as FKHRL1), FOXO4 (previously known as Afx), and FOXO6.

The DNA-binding domain (Forkhead box) is located in the N-terminal portion of these proteins, while the transactivation domain is located in the C-terminal portion. Furthermore, a 'nuclear export sequence' and a 'nuclear localization signal' have been delineated. These motifs allow FOXO factors to shuttle in and out of the nucleus (see below). FOXO proteins may be post-translationally modified by phosphorylation and/or acetylation at differentially conserved serine/threonine and lysine residues respectively. Structural features of FOXO proteins have been detailed in recent reviews (Barthel et al. 2005, Greer \& Brunet 2005).

\section{Molecular regulation of FOXO transcription factors}

As illustrated in Fig. 1, multiple molecular mechanisms regulate FOXO transcription factor functions. Some control subcellular FOXO localization, while others modulate FOXO transactivation properties. Furthermore, FOXO factor abundance is regulated by site-specific protein cleavage or through the control of foxo gene expression.

Subcellular localization FOXO factors shuttle between nucleus and cytoplasm. This represents a major event controlling FOXO activity that results from changes in FOXO phosphorylation. Two main classes of stimuli trigger FOXO phosphorylation with opposing effects on FOXO localization. 
On one hand, phosphorylation of FOXO proteins in response to growth factors such as insulin-like growth factor-I (IGF-I), erythropoietin, epidermal growth factor (EGF), or nerve growth factor causes exclusion from the nucleus. For many growth factor-activated protein kinases, the specific phosphorylation sites are known. These include Akt (also known as protein kinase $\mathrm{B}(\mathrm{PKB})$ ) and serum and glucocorticoid inducible kinase (SGK), which are activated through the PI3K pathway, dual speciticity tyrosine $(\mathrm{Y})$ phosphorylation regulated kinase 1 (DYRK1), and casein kinase 1 (CK1) (Biggs et al. 1999, Brunet et al. 1999, 2001, Rena et al. 2002).

On the other hand, phosphorylation of FOXO proteins in response to oxidative stress, involving, for example, Jun-Nterminal kinase (JNK) or mammalian Ste20-like kinase, results in FOXO import in the nucleus. FOXO residues targeted by these kinases are different from those targeted by growth factor-regulated kinases (Essers et al. 2004, Matsumoto \& Accili 2005, Lehtinen et al. 2006). Interestingly, the effect of oxidative stress appears to prevail on the effect of growth factors (see Fig. 2; Wang et al. 2005).

To date, no specific phosphatase dephosphorylating FOXO has been identified.

Transcriptional regulation by FOXO proteins Nuclear FOXO proteins interacting with DNA and partner proteins regulate the transcription of specific target genes through multiple modes of action as depicted in Fig. 3 (reviewed in Barthel et al. 2005). FOXO can recruit transcriptional co-activators (Fig. 3A) or co-operating
DNA-binding transcription factors (Fig. 3B). Alternatively, FOXO factors may repress transcription by competing with activatory transcription factors for a common binding site in a gene promoter (Fig. 3C; Kitamura et al. 2002). FOXO factors may also act as co-activators or co-repressors (Fig. 3D and E), thereby regulating transcription through promoters which lack FOXO-binding sites.

\section{Modulation of FOXO transcriptional properties} Covalent modifications (phosphorylation and acetylation) as well as protein-protein interactions can modulate the transactivation potential and the DNA binding of FOXO. FOXO-binding partners can modulate FOXO transactivation properties either positively (e.g. $\beta$-catenin; Essers et al. 2005) or negatively (e.g. PPAR $\gamma$ or the androgen receptor; Dowell et al. 2003, Li et al. 2003).

In addition to governing nuclear/cytoplasm shuttling, phosphorylation of FOXO can decrease its inherent transactivation potential notably by disrupting the interactions with co-activators (Perrot \& Rechler 2003, Puigserver et al. 2003, Tsai et al. 2003).

FOXO transcription factors are acetylated by p300 and CBP, co-activators displaying histone acetyltransferase activity (Chan \& La Thangue 2001), at several conserved lysine residues, many of which are located in the DNA-binding domain (Fukuoka et al. 2003, van der Horst et al. 2004). Apparently, acetylation of FOXO factors decreases their transactivation potential, possibly by reducing their DNAbinding activity. Given that the requirement for FOXO DNA-binding activity may vary among the different target

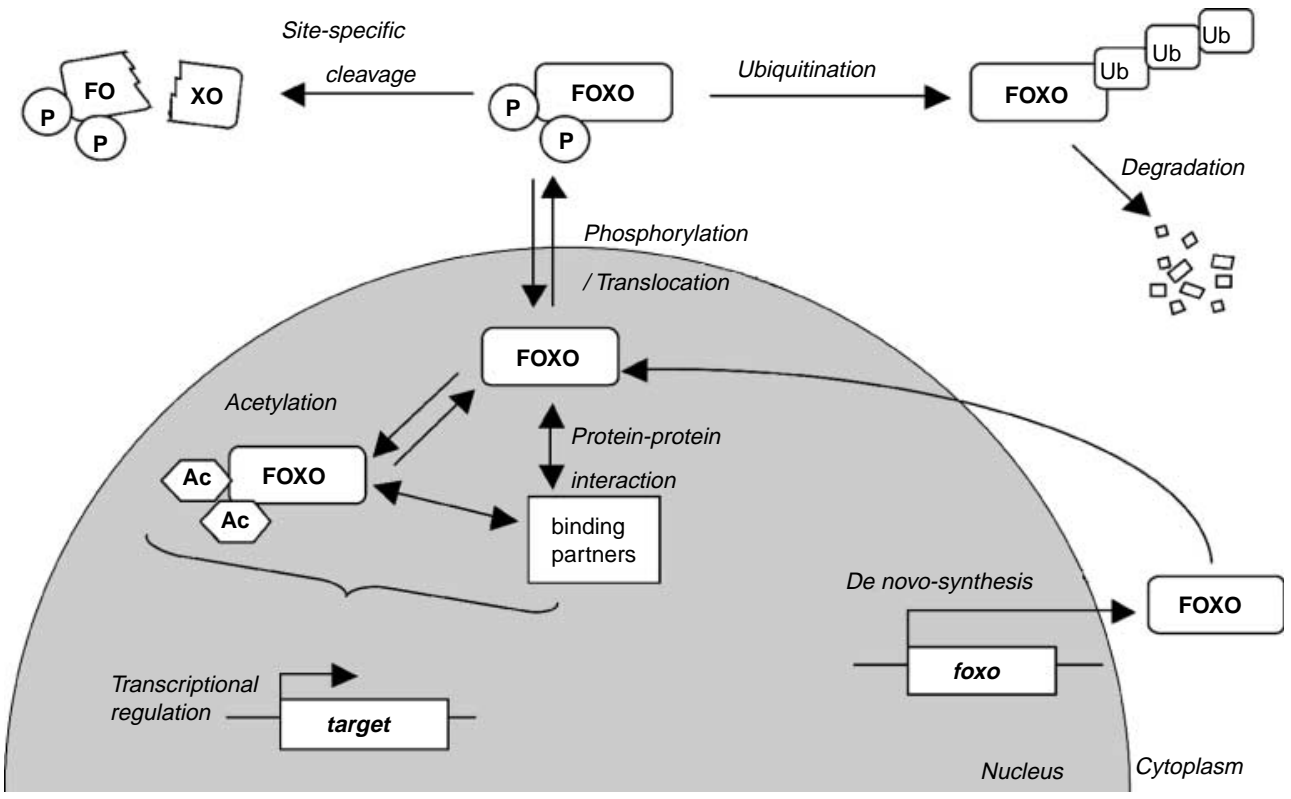

Figure 1 Overview of the main mechanisms regulating FOXO transcription factors. Multiple mechanisms control FOXO transcription factor activity. Some are reversible, such as interaction with other proteins, acetylation, phosphorylation, or translocation, while others are irreversible, such as ubiquitin-dependent degradation or sitespecific cleavage by proteases. Ub, ubiquitin; P, phosphate group; Ac, acetyl group. 


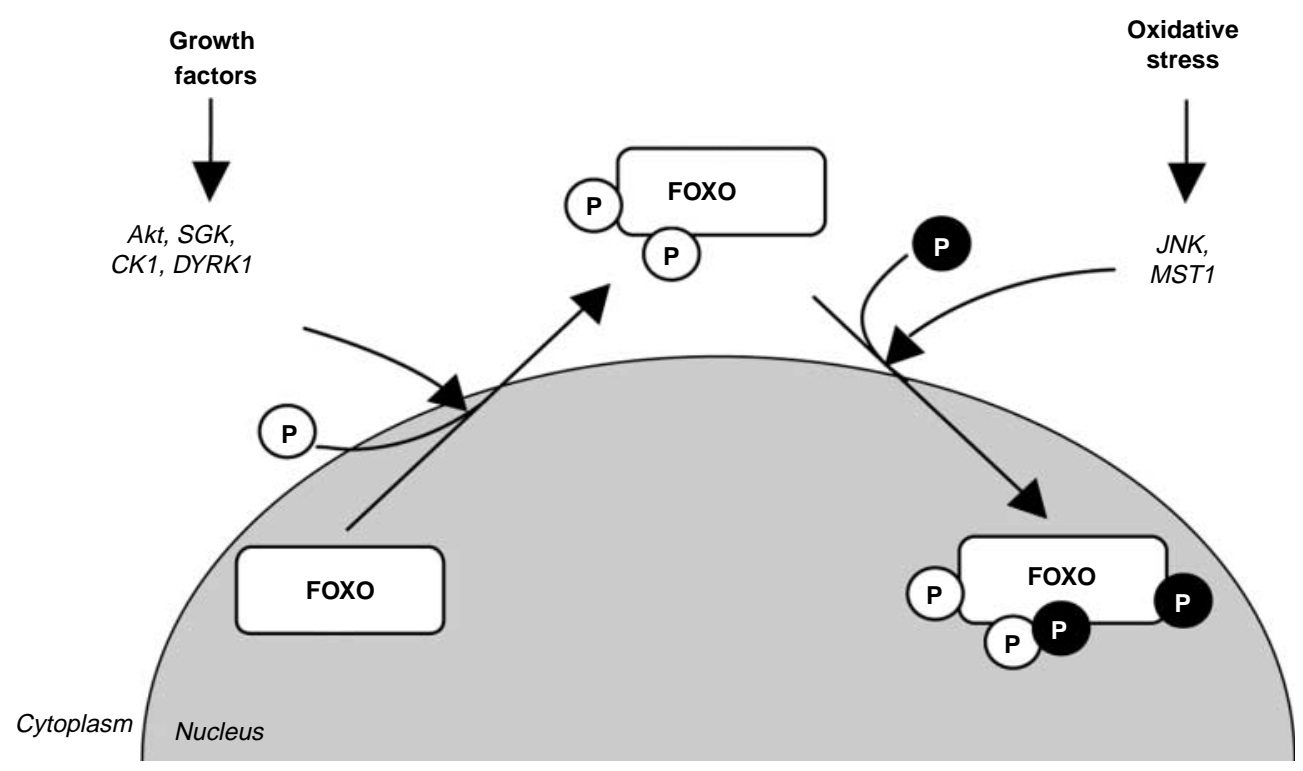

Figure 2 Antagonistic effects of growth factors versus oxidative stress-dependent phosphorylations on the subcellular localization of FOXO.

genes, acetylation may represent a mechanism controlling FOXO factor specificity. Deacetylation of FOXO proteins has been shown to result from the activity of SIRT1, a member of the Sir2 family of NAD-dependent deacetylases (Brunet et al. 2004, Motta et al. 2004, van der Horst et al. 2004). The effects of SIRT1 on FOXO function are complex and vary depending upon the FOXO target genes. SIRT1 appears to promote transcription of FOXO target genes involved in stress resistance, while decreasing transcription of genes involved in apoptosis (Greer \& Brunet 2005). This is consistent with the proposal that acetylation/deacetylation of FOXO protein may switch target specificity.

Altogether, interaction with other proteins, phosphorylation, and acetylation offer a large spectrum of options for the fine tuning of FOXO function in complement to the master switch operated by the control of FOXO factors' nuclear localization.

Regulated levels of FOXO proteins mRNA levels of the different foxo gene subtypes vary from tissue to tissue in mammals (Furuyama et al. 2000) and can be modulated under some circumstances (Furuyama et al. 2002, Richards et al. 2002). These observations highlight that the transcription of foxo genes is subject to regulation.

Probably, a more important determinant of FOXO protein expression is its rate of degradation. After ubiquitination, FOXO proteins are degraded by proteolysis through the proteasome pathway (Vogt et al. 2005). This cytosolic process may be favored by FOXO phosphorylation and/or deacetylation (Hu et al. 2004, Kitamura et al. 2005). A possible role for AMPK in regulating FOXO stability has been suggested in liver (Barthel et al. 2002). Recent findings indicate that ubiquitination of the different FOXO proteins may be accomplished by different E3 (ubiquitin ligase) complexes as a consequence of different regulatory processes (Huang et al. 2005).

Site-specific cleavage In early stages during Fas-induced apoptosis in lymphoid cells, FOXO3 protein is cleaved by a caspase-3-like protease (Charvet et al. 2003). This cleavage separates the N-terminal DNA-binding domain of FOXO3 from its C-terminal transactivation domain and occurs at a caspase- 3 consensus cleavage site (amino acid sequence: $\left.\mathrm{DELD}^{304}\right)$. Interestingly, similar sequence motifs are conserved in FOXO1 and FOXO4. Site-specific cleavage probably represents more than an inactivation pathway, the N-terminal fragment being able to translocate to the nucleus and having the potential to affect the transcription of FOXO target genes (Charvet et al. 2003).

\section{Cell functions regulated by FOXO}

FOXO factors contribute to the regulation of various processes such as cell cycle progression, cell size determination, cell death, cell differentiation, resistance to stress, and energetic metabolism (reviewed in Greer \& Brunet 2005). In Table 1, we list the best characterized FOXO-regulated target genes. Recent experiments aiming to identify FOXO target genes at a large scale have confirmed the plethora of cellular functions concerned (Modur et al. 2002, Ramaswamy et al. 2002, Murphy et al. 2003).

Role of FOXO in development, integrated physiology, and diseases

Implication of FOXO in development Foxo1, foxo3, and foxo 4 genes have been knocked out in mice (Castrillon $e t$ al. 
A

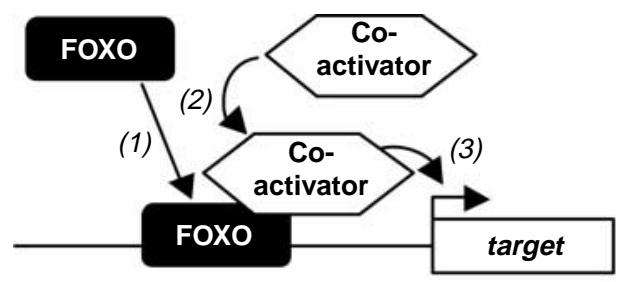

B

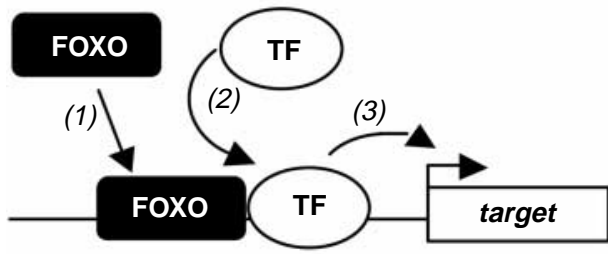

C
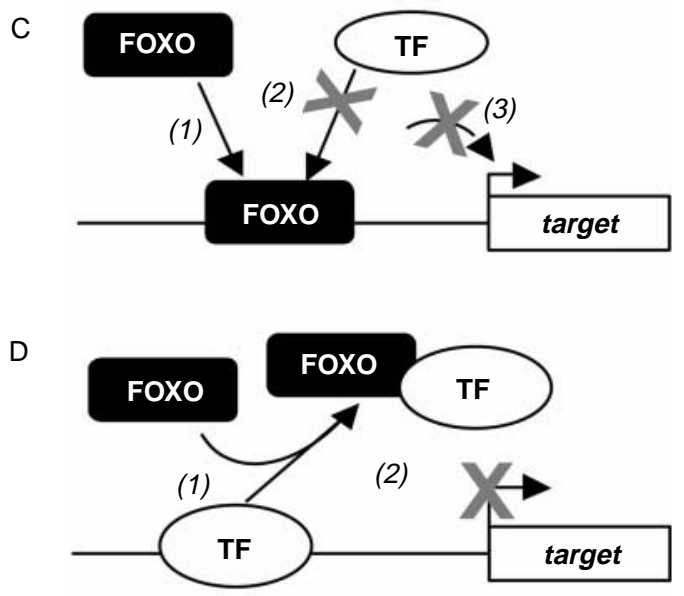

E

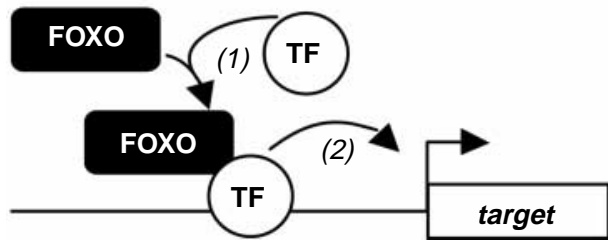

Figure 3 Different FOXO modes of transcriptional regulation. (A) Recruitment of co-activators. (B) Co-operative binding with transcription factors. (C) Competition with transcription factors. ( $\mathrm{D}$ and $\mathrm{E}$ ) Co-repression or co-activation (independently of FOXO DNA-binding activity). TF, transcription factor.

2003, Hosaka et al. 2004). While heterozygous Foxo1 ${ }^{+/-}$mice are viable, homozygous Foxo1 ${ }^{-/-}$mice are embryonic lethal, emphasizing the importance of FOXO function in embryonic development. Foxo1 ${ }^{-/-}$mice embryos are smaller and die at embryonic day $10 \cdot 5$. The primary defect causing lethality in Foxo1 ${ }^{-/-}$mice is apparently an impaired vascularization. Consistently, experiments in Foxo1 ${ }^{+/-}$mice embryos have shown that FOXO1 is highly expressed in developing vasculature (Furuyama et al. 2004, Hosaka et al. 2004).
Interestingly, FOXO factors continue to contribute to vascularization after birth (Potente et al. 2005). In mature endothelial cells, the inhibition of FOXO1 activity by angiopoietin 1 regulates several genes involved in apoptosis and vessel destabilization/remodeling (Daly et al. 2004).

In mice, FOXO factors may also have a role in the developing brain. FOXO1, FOXO3, and FOXO6 are expressed in a spatially and temporally restricted manner (Hoekman et al. 2006).

Evidence for a role of FOXO factors in embryonic development has also been provided in the frog Xenopus laevis, where $x$ foxo 1 and $x$ foxo 3 (foxo orthologs) present distinct spatial and temporal patterns of expression (Pohl et al. 2004).

Implication of FOXO factors in reproductive function Foxo $3^{-/-}$female mice have a very singular phenotype: being initially fertile, they become infertile after 15 weeks of age (Castrillon et al. 2003, Hosaka et al. 2004). This secondary infertility appears to be due to premature and global follicular activation leading to oocyte death and subsequent precocious depletion of the follicle population. Accordingly, under normal circumstances, Akt and FOXO3 are expressed in oocytes, mostly in primordial and primary follicles. Communication between oocytes and their surrounding granulosa cells is mediated by stem cell factor (SCF), which regulates primordial to primary follicle transition and subsequent follicle development. In oocytes, SCF activates Akt and suppresses FOXO3 activity through nuclear exclusion. Thus, it has been proposed that granulosa cell-derived SCF will act on the follicular development through activation of an Akt-FOXO3 pathway in oocytes (Reddy et al. 2005). There is also evidence for an implication of FOXO1 in ovarian functions, as FOXO1 can regulate follicule-stimulating hormone-dependent proliferation of granulosa cells (Cunningham et al. 2003, 2004, Park et al. 2005).

Implication of FOXO in cancer The pivotal role of FOXO in cell fate decisions, depending upon the balance between growth factor stimulation versus cellular stress and damage, would predict that FOXOs are tumor suppressors. Indeed, circumstantial and direct evidence suggests the implication of FOXO factors in cancer. Foxo genes (foxo1, foxo3, and foxo 4) were found at chromosomal breakpoints in human tumors (Galili et al. 1993, Parry et al. 1994, Borkhardt et al. 1997, Hillion et al. 1997). Nuclear exclusion of FOXO3 in primary breast tumors correlates with PI3K activation and poor survival of the patients (Hu et al. 2004). FOXO factors reduce tumorigenicity in nude mice (Ramaswamy et al. 2002, Hu et al. 2004, Yang et al. 2005). Furthermore, FOXO proteins interact with many oncogenes (i.e. $\beta$-catenin; Essers et al. 2005) or tumor suppressors such as p53 (Brunet et al. 2004).

Implication of FOXO in aging A link between FOXO factors and aging has initially been observed in invertebrates. In the nematode C. elegans, DAF-16, the only foxo gene ortholog, regulates lifespan (reviewed in Baumeister et al. 
Table 1 Some of the best characterized FOXO target genes and regulated cellular processes

Cellular process

\section{Target gene}

Cyclin-dependent kinase inhibitor 1B (p27)

Cyclin-dependent kinase inhibitor 1A (p21)

Cyclin D1

Cyclin D2 (ccnd2)

Cyclin G2

Growth arrest and DNA damage-inducible protein 45

DNA damage-binding protein 1

Manganese superoxide dismutase

Catalase

Trail

Fas ligand

Bcl-6

$\mathrm{Bcl}-2$ interacting mediator of cell death

B-cell translocation gene 1

Atrogenin-1 (MAFbx)

Glucose-6-phosphatase

Phosphoenolpyruvate carboxykinase

Apolipoprotein CIII

Pyruvate dehydrogenase kinase 4
Cell cycle (G1/S transition)

Cell cycle (G1/S transition)/differentiation (adipocyte)

Cell cycle (G1/S transition)

Cell cycle (G1/S transition)

Cell cycle (G0/G1-S transition)

Cell cycle (G2 arrest)/DNA repair

DNA repair

ROS detoxification

ROS detoxification

Cell death

Cell death

Cell death

Cell death

Differentiation (erythrocytes)

Muscle atrophy

Metabolism

Metabolism

Metabolism

Metabolism
Reference

Medema et al. (2000)

Seoane et al. (2004), Nakae et al. (2003)

Ramaswamy et al. (2002)

Ramaswamy et al. (2002)

Martinez-Gac et al. (2004)

Tran et al. (2002)

Tran et al. (2002)

Kops et al. (2002)

Nemoto \& Finkel (2002)

Modur et al. (2002)

Brunet et al. (1999)

Ramaswamy et al. (2002)

Dijkers et al. (2000)

Bakker et al. (2004)

Sandri et al. (2004)

Nakae et al. (2001)

Nakae et al. (2001)

Altomonte et al. (2004)

Furuyama et al. (2003)
2006). In Drosophila melanogaster, dFOXO regulates agelinked decline of cardiac function and longevity (Giannakou et al. 2004, Hwangbo et al. 2004, Wessells et al. 2004).

There is so far no direct evidence which would link FOXO factors to longevity of mammals. FOXO factors are involved in cellular resistance to stress, promoting reactive oxygen species (ROS) detoxification, DNA repair, and cell cycle arrest to allow time for the repair process (Table 1). Therefore, FOXO could reduce detrimental effects of aging. Interestingly, some of the FOXO targets (like MnSOD) are conserved from worm to mammals. Moreover, mice that are deficient in insulin or the IGF-I receptor have an increased lifespan and are more resistant to oxidative stress stimuli (Bluher et al. 2003, Holzenberger et al. 2003). It is possible that FOXO factors, normally leaving the nucleus after insulin/IGF-I stimulation, mediate in part the longevity of these knockout mice. Furthermore, the effects of SIRT1 on FOXO function may be linked to aging, as Sir2, the SIRT1 orthologs in yeast, worms, and flies, have been linked to the longevity of these organisms (Tissenbaum \& Guarente 2001, Rogina \& Helfand 2004).

\section{Implication of FOXO factors in energy homeostasis}

In mammals, insulin has a key role in regulating glucose homeostasis and co-ordinating body energetic metabolism. Many aspects of the response to insulin require regulation of gene expression. As a major downstream target of insulinsignaling pathway, FOXO transcription factors may mediate adaptive responses of the gene expression program in many insulin target tissues (Barthel et al. 2005). There is evidence for this notably in liver (Puigserver et al. 2003), muscle (Furuyama et al. 2003), adipocytes (Nakae et al. 2003), and pancreatic $\beta$ cells (Kitamura et al. 2002). Furthermore, recent findings have indicated that FOXO1 mediates the action of insulin and leptin in the hypothalamus, controlling the production of different neuropeptides and the feeding behavior in mice (Kim et al. 2006, Kitamura et al. 2006). Thus, FOXO contributes to the orchestration of energy homeostasis by acting in the main energy consuming and storing tissues, as well as in the endocrine and central nervous system.

\section{Part II: FOXO in pancreatic $\beta$ cells}

Pancreatic $\beta$ cells are located in the islets of Langerhans which constitute the endocrine compartment of the pancreas. $\beta$ Cells produce insulin and secrete it in response to elevations in circulating blood glucose and to other signaling molecules, providing a key contribution to glucose homeostasis and to the coordination of metabolism within the body. FOXO factors are expressed in $\beta$ cells, and many pathways that have been shown to regulate FOXO function in other tissues are active in $\beta$ cells. The following paragraphs will summarize information about these pathways and present recent data pointing to an emerging role of FOXO factors in $\beta$ cells.

\section{FOXO subtypes expressed in $\beta$ cells}

FOXO1 is the most predominantly expressed FOXO factor in isolated mice islets as well as in the $\beta$ TC-3 $\beta$ cell line. In mice islets, FOXO3 is expressed at a lower level, while FOXO4 is apparently undetectable (Kitamura et al. 2002). FOXO1 has also been shown to be expressed in isolated human islets (Contreras et al. 2002). Interestingly, foxo1 mRNA levels are more elevated in islets of diabetic when 


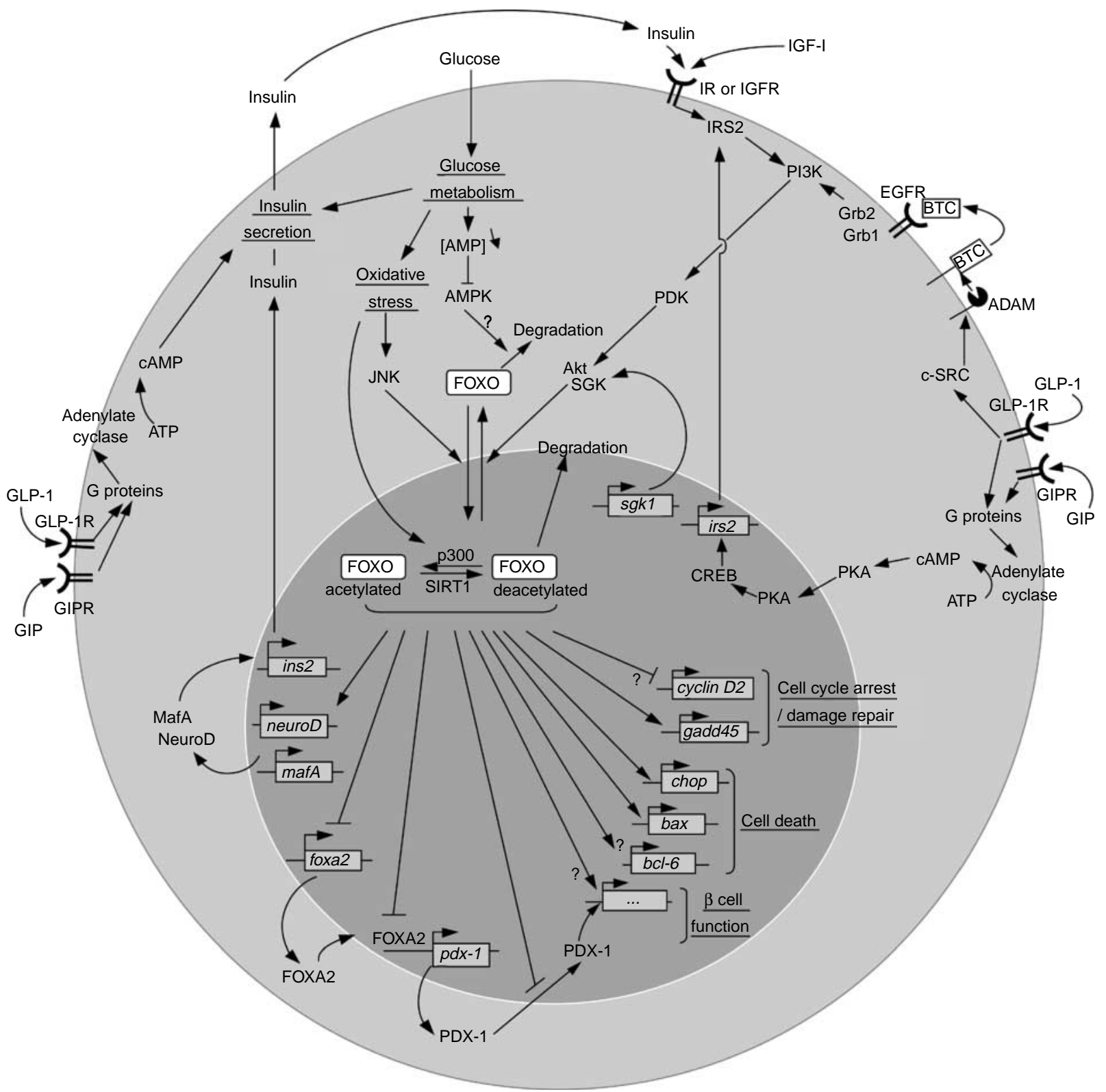

Figure 4 Overview of FOXO-linked signaling pathways and FOXO targets in $\beta$ cells. See details in the text.

compared with non-diabetic patients, but the reason for this is unknown (Del Guerra et al. 2005).

\section{FOXO-linked pathways in $\beta$ cells}

As shown in Fig. 4, several signaling pathways may lead to regulation of FOXO transcription factors in pancreatic $\beta$ cells.

PI3K-Akt pathway PI3K-Akt pathway is a major upstream signaling module leading to the phosphorylation of FOXO factors and their exclusion from the nucleus. In $\beta$ cells, FOXO is phosphorylated following the activation of the PI3K-Akt pathway by insulin, IGF-I, glucose, glucagon-like peptide-1 (GLP-1), or glucose-dependent insulinotropic polypeptide (GIP) (Trumper et al. 2000, 2001, Wrede et al. 2002, Buteau et al. 2006).

The binding of IGF-I or insulin to their receptors results in the receptor autophosphorylation on tyrosine residues and in the tyrosine phosphorylation of insulin receptor substrates (IRS) by the receptor tyrosine kinases. IRS may then activate PI3K, leading to 3-phosphoinositide dependent protein kinase-1 (PDK) activation and finally Akt activation. 
GLP-1 and GIP are glucoincretin hormones that are released from gut cells upon food intake and potentiate glucose activation of insulin secretion by $\beta$ cells. A mechanistic explanation for Akt activation by insulin secretagogues would be an autocrine effect of secreted insulin through its binding to the insulin receptor (IR) at the surface of $\beta$ cells (Ohsugi et al. 2005). Consistently, in cultured cells, glucose regulates FOXO1 through the insulin signaling pathway (Martinez et al. 2006). However, the ability of insulin to drive activation of the PI3K/Akt pathway in a physiological context, as well as the real physiological significance of any insulin feedback on $\beta$ cells, is still controversial (Leibiger et al. 2002). Alternative mechanisms have been proposed for the activation of PI3K by GLP-1. On the one hand, binding of GLP-1 to its receptor (GLP-1R) can produce c-SRC-mediated activation of a membrane-bound metalloprotease, which would cleave betacellulin membrane integral precursor and release betacellulin soluble ligand (BTC). BTC would in turn activate EGF receptor and PI3K, presumably independently of IRS, but with the help of the structurally related GAB1/GRB2 proteins (Buteau et al. 2003). On the other hand, GLP-1 can promote activation of PI3K by increasing expression of IRS-2, through G-protein-dependent activation of adenylyl cyclase, formation of cAMP, activation of PKA, and finally, activation of the CREB transcription factor (Holz \& Chepurny 2005).

In spite of distinct receptors for GIP (GIPR) and GLP-1 (GLP-1R), the two glucoincretins share most of their downstream mitogenic signaling pathways (Trumper et al. 2001). Thus, it is likely that the mechanisms of activation of the PI3K-Akt-FOXO pathway by GIP are similar to the one triggered by GLP-1.

In summary, the PI3K-Akt-FOXO pathway is regulated by multiple signals in the $\beta$ cell.

SGK1 In the Min6 $\beta$ cell line, expression of SGK1 mRNA depends on the glucose concentration (Fig. 5B). Increased expression of SGK1 at low glucose correlates with decrease of FOXO level in the nucleus (Fig. 5A and Martinez et al. 2006). This suggests that regulation of SGK1 may also contribute to the glucose responsiveness of FOXO factors in $\beta$ cells.

JNK pathway Activation of JNK due to cellular stress of various origin (including oxidative stress) may lead to phosphorylation of FOXO factors and drive translocation of FOXO factors into the nucleus. In pancreatic $\beta$ cells, oxidative stress is induced when glucose levels are high. In diabetes, chronic hyperglycemia inducing oxidative stress is thought to cause $\beta$ cell dysfunction (Kaneto et al. 2005). Recent findings indicate that activation of JNK by oxidative stress can result in FOXO1 translocation to the nucleus in mouse $\beta$ cells (Kawamori et al. 2006).

FOXO acetylation/deacetylation An important molecular mechanism regulating FOXO protein functions consists in acetylation/deacetylation modifications. SIRT1 deacetylase is known to deacetylate FOXO proteins, while CBP and p300 are known to acetylate FOXO proteins. As mentioned earlier in the text, these modifications are likely
A

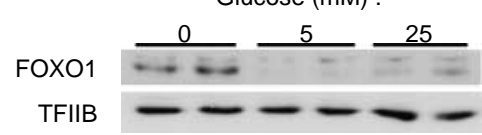

B

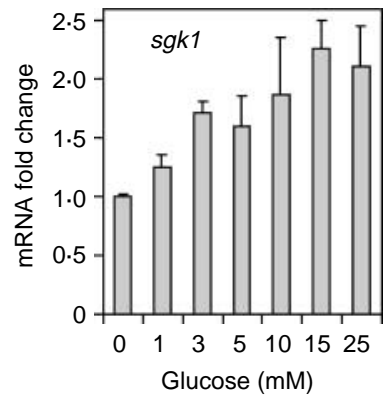

C

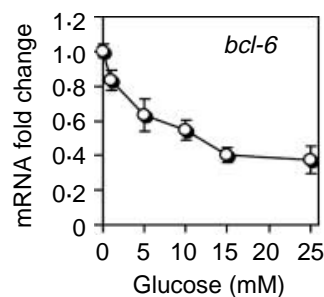

D

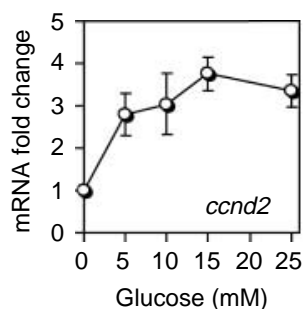

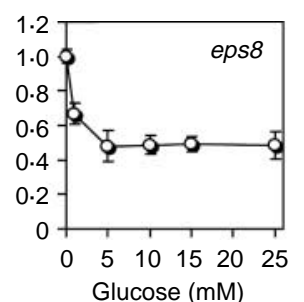
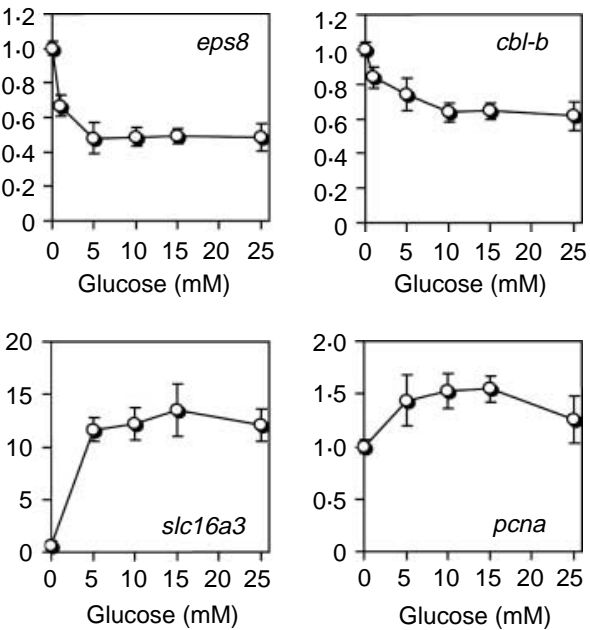

Figure 5 Regulation of SGK and FOXO target gene expression by glucose in Min6 cells. Min6 cells were cultured for $24 \mathrm{~h}$ in a medium with $1 \%$ serum, at indicated glucose concentration as previously described (Glauser \& Schlegel 2006). (A) Nuclear fractions were analyzed by western blot with the antibody raised against FOXO1 (\#9462, Cell Signaling) and the general transcription factor TFIIB (loading control; Santa Cruz Biotechnology). FOXO1 is detected in the nucleus at low but not at high glucose concentrations. (B-D) Total RNA was analyzed by quantitative real-time RT-PCR for indicated genes (normalized with $18 \mathrm{~S}$ rRNA content and depicted as mean \pm s.D., $n=3$ ). Genes known to be up-regulated by FOXO1 in other cell systems (C) are up-regulated at low glucose concentrations (when FOXO1 is present in the nucleus). Inversely, genes known to be down-regulated by FOXO1 in other cell systems (D) are up-regulated at high glucose concentrations (when FOXO1 is absent from the nucleus). 
determinants in FOXO transcription factor target specificity and may be key regulatory steps in determining the balance between the resistance to stress effects and the pro-apoptotic effects of FOXO factors.

SIRT1 is expressed in $\beta$ cells and is involved in $\beta$ cell physiology. Indeed, increasing the level of SIRT1 in the pancreatic $\beta$ cells of transgenic mice results in a more efficient glucose handling due to enhanced glucose-stimulated insulin secretion (Moynihan et al. 2005). Recent experiments have shown that FOXO1 was subject to acetylation and deacetylation in $\beta$ cells, and suggested the involvement of SIRT1 and CBP/p300, which interact with FOXO1 in $\beta$ cells (Kitamura et al. 2005).

AMPK AMPK pathway is regulated by the intracellular metabolism, in particular, by the energetic substrates that are available. Under conditions of energy restriction, an increase in AMP levels leads to AMPK activation; reciprocally, under conditions of high energy availability, a decrease in AMP levels inhibits AMPK activation. In the $\beta$ cell, variations in glucose concentrations over the physiological range efficiently modulate AMPK activity, which in turn regulates insulin secretion and gene expression (Rutter et al. 2003). Under conditions of energy restriction, activated AMPK might promote FOXO degradation in the $\beta$ cells, thereby regulating FOXO activity as proposed for the liver (Barthel et al. 2002).

\section{FOXO targets and physiological role of FOXO in $\beta$ cells}

The glucose/IGF-I/GLP-1/GIP-induced activation of Akt in $\beta$ cells correlates with increased survival. Overexpression of Akt in $\beta$ cells in transgenic mice promotes $\beta$ cell survival and increases $\beta$ cell size (Dickson \& Rhodes 2004). Moreover, glucose can promote $\beta$ cell proliferation in culture through the activation of PI3K-Akt pathway (Srinivasan et al. 2002). In contrast, free fatty acids significantly inhibit glucose/IGF-I-induced activation of Akt in $\beta$ cells, correlating with reduced $\beta$ cell growth and increased $\beta$ cell apoptosis (Dickson \& Rhodes 2004). GLP-1 also inhibits apoptosis through activation of the PI3K/Akt pathway (Wang et al. 2004, Li et al. 2005). Thus, Akt appears to be an important positive regulator of $\beta$ cell mass inhibiting apoptosis and promoting $\beta$ cell proliferation and expansion.

In the last few years, several studies using transgenic mice have substantiated an important role of FOXO as a downstream effector of insulin/IGF-PI3K-Akt signaling pathway in the regulation of $\beta$ cell function and growth. In Irs $2^{-/-}$mice, which lack IRS2 and suffer from $\beta$ cell failure, ablation of one allele of foxo1 is sufficient to restore $\beta$ cell proliferation. This indicates that FOXO1 is an important target of insulin/IGF signaling pathway, downstream of IRS2 (Kitamura et al. 2002). Similarly, deletion of one allele of foxo 1 was found to rescue $\beta$ cell proliferation in $\beta \mathrm{Pdk} 1^{-/-}$mice $(\beta$ cell-specific knockout for Pdk1), alleviating their diabetic phenotype (Hashimoto et al. 2006). Transgenic mice that express insulin receptors
(INSR) only in liver, brain, and $\beta$ cells (Insr ${ }^{-/-}$rescued by insr transgene under the control of transtyretin promoter) have high levels of circulating insulin compensating for insulin resistance in muscle and fat. Increased $\beta$ cell mass can explain this compensatory effect, which is reversed by the expression of a constitutively nuclear form of FOXO1 (Okamoto et al. 2006). In another transgenic mouse model, pancreas-restricted production of IGF-II acts in a paracrine fashion to promote $\beta$ cell proliferation. In this model, expression of a constitutively nuclear form of FOXO1 is also able to block the proliferation response (Okamoto et al. 2006). Altogether, these findings converge to show that expansion of $\beta$ cell mass in response to insulin/IGF signaling requires FOXO1 nuclear exclusion.

A probable way through which FOXO1 mediates insulin/IGF effects on $\beta$ cell proliferation is through downregulation of PDX1. PDX1 is a major $\beta$ cell transcription factor that controls $\beta$ cell growth and function. PDX1 and FOXO1 exhibit mutually exclusive patterns of nuclear localization (Kitamura et al. 2002). Two mechanisms by which FOXO may regulate PDX1 have been proposed. First, it was suggested that FOXO1 would control the subcellular localization of PDX1 (Kawamori et al. 2006). Secondly, FOXO1 may function as a repressor of FOXA2-dependent expression from the Pdx1 promoter (Kitamura et al. 2002).

FOXO1 factor is an important mediator of GLP-1 and GIP effects on $\beta$ cell proliferation and survival. As mentioned earlier, GLP-1 activates the PI3K-Akt pathway inhibiting FOXO through its exclusion from the nucleus. Expression of constitutively nuclear FOXO1 prevents the proliferative and anti-apoptotic effects of GLP-1 (Buteau et al. 2006). GLP-1 up-regulates pdx1 and foxa2 (two FOXO1 target genes), transcription of which is repressed by nuclear FOXO1. Induction of $\mathrm{pdx} 1$ and foxa 2 may contribute to FOXO exclusion-dependent effect of GLP-1 on proliferation and survival. Similarly, GIP induces FOXO1 nuclear exclusion. This results in the down-regulation of the pro-apoptotic gene $b a x$, a FOXO1 target, and promotes $\beta$ cell survival (Kim et al. 2005).

Other transcriptional targets of FOXO1 in $\beta$ cells include maf $A$ and neuro $D$ genes, which code for transcription factors that are important for $\beta$ cell function, notably regulating the expression of the insulin-coding gene Ins2 (Kitamura et al. 2005). Upon oxidative stress caused by hyperglycemia, the nuclear localization of FOXO1 is required for the induction of MafA and NeuroD expression. Interestingly, under these circumstances, FOXO1 is initially acetylated and subsequently deacetylated, which not only activates transcription but also promotes ubiquitin-dependent degradation of FOXO1 by the proteasome and reduces the half-life of FOXO1. These findings suggest that FOXO1 orchestrates a compensatory response to transient metabolic stress aiming at maintaining $\beta$ cell function, but that this response may be inefficient for longer term responses to hyperglycemia since FOXO1 is ultimately degraded. In addition, there is evidence that chop and gadd45 are FOXO targets, up-regulated at low glucose in $\beta$ cells (Martinez et al. 2006). Thus, FOXO may be 
involved in $\beta$ cell responses to stress, including cell cycle arrest, DNA damage repair, or apoptosis.

FOXO most likely regulates the transcription of additional target genes in $\beta$ cells. A list of FOXO1 target gene candidates was obtained by crossing a list of known FOXO1-regulated genes (Ramaswamy et al. 2002) and a list of glucose-responsive genes in Min6 cells (DA Glauser, $\mathrm{T}$ Brun, BR Gauthier and W Schlegel, unpublished observations), as glucose regulates FOXO in this cell line (Fig. 5A and Martinez et al. 2006). Six probable targets were thus identified (Fig. 5C and D). Among these, cyclin D2, which is known to be down-regulated by FOXO1 (Ramaswamy et al. 2002), is down-regulated at low glucose when FOXO1 is abundant in the nucleus. As cyclin D2 represents a major checkpoint in the regulation of $\beta$ cell cycle progression (Georgia \& Bhushan 2004, Kushner et al. 2005), its regulated expression possibly mediates the FOXO effect on $\beta$ cell proliferation. Further investigations are required to elucidate the mechanisms downstream of FOXO which impact on $\beta$ cell physiology.

\section{Part III: perspectives}

Why is FOXO of particular interest to the biology of the endocrine pancreas?

\section{A conserved and fundamental function for FOXO}

factors In any living organism, nutrient availability and growth are linked, and most organisms deal with an adverse environment by the activation of a repertoire of anti-stress responses. FOXO factors, which decide between proliferation and stress handling, are thus central to very fundamental biology (Fig. 6). Nutrient restriction depleting ATP levels will decrease growth and prompt cells to spend all remaining resources on maintenance. In contrast, when nutrients are very abundant, high rates of oxidative metabolism may

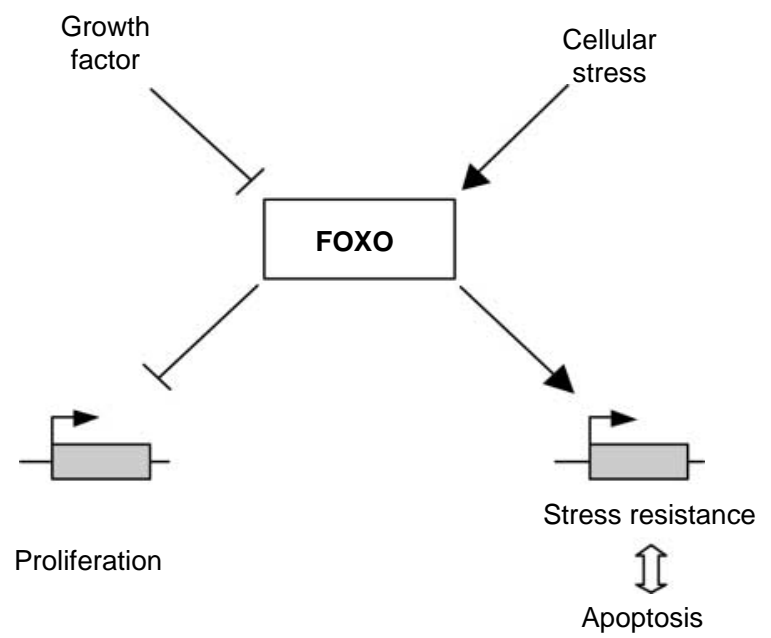

Figure 6 FOXO as integrator of growth and stress signals. produce detrimental reactive oxygen species. Both of these inappropriate energetic situations may thus cause insults to cells, such as DNA damage or protein misfolding resulting from lack of ATP in the endoplasmic reticulum. If such insults are too important or inappropriately controlled, then they may cause apoptosis.

In mammals, the endocrine pancreas sensing the circulating nutrients will produce insulin and glucagon, which in turn handle nutrient homeostasis for the whole organism and regulate growth and differentiation of various organs and tissues. Handled nutrient and hormone levels feed back to the $\beta$ cells, such that the functionality of the endocrine compartment can be maintained and its performances adapted to varying insulin demand. Indeed, insulin, which likely act in an autocrine manner, as well as glucoincretins are growth/survival factors for $\beta$ cells. On the other hand, metabolism of nutrients contributes to oxidative stress also in the endocrine pancreas and elicits cellular stress signaling. Thus, FOXO factors, which sense growth signals and cellular stress and relate these to cellular responses, are part of the most important regulatory system governing function, proliferation, differentiation, and survival of the pancreatic $\beta$ cell (Fig. 7). FOXO-dependent mechanisms function on different time scales. First, FOXO may help $\beta$ cells cope with acute periods of oxidative stress produced by transient oscillations of glycemia, either by orchestrating the resistance to intracellular stress or by enhancing insulin production and its endocrine action to decrease glycemia. Secondly, in the long term, FOXO factors control the adaptation of $\beta$ cell mass and the ability of the endocrine pancreas to handle future metabolic loads.

FOXO in diabetes, a possible therapeutic target? These features point to a possible role of FOXO in human diabetes mellitus, especially in type 2 diabetes. Type 2 diabetes is characterized by hyperglycemia that results from a $\beta$ cell failure to produce sufficient insulin to meet the body's demand. This failure may result from a dysfunction of insulin secretion and/or from a decrease in $\beta$ cell mass (Rhodes 2005). Obese patients who develop insulin resistance in peripheral tissues and therefore have a high insulin demand reach the limits of their endocrine pancreas earlier in life. This could partially explain the high prevalence of type 2 diabetes in obese patients. Compensatory adaptation of $\beta$ cell mass, which - in mice models (Okamoto et al. 2006) - involves FOXO factors, must have failed in those patients. Furthermore, FOXO-mediated $\beta$ cell apoptosis may contribute to the long-term deleterious effect of hyperglycemia on $\beta$ cell mass. Thus, FOXO factors are very likely involved in the progression of type 2 diabetes and may be regarded as possible therapeutic targets.

In addition to controlled diet and exercise, three main types of approaches are used, to date, to treat diabetes: (i) oral drugs, which mostly aim at reducing glucose production in liver, reducing glucose absorption from the digestive tract, or stimulating the secretory capacity of $\beta$ cells; (ii) insulin injections; and (iii) transplantation of islets from organ donors; 


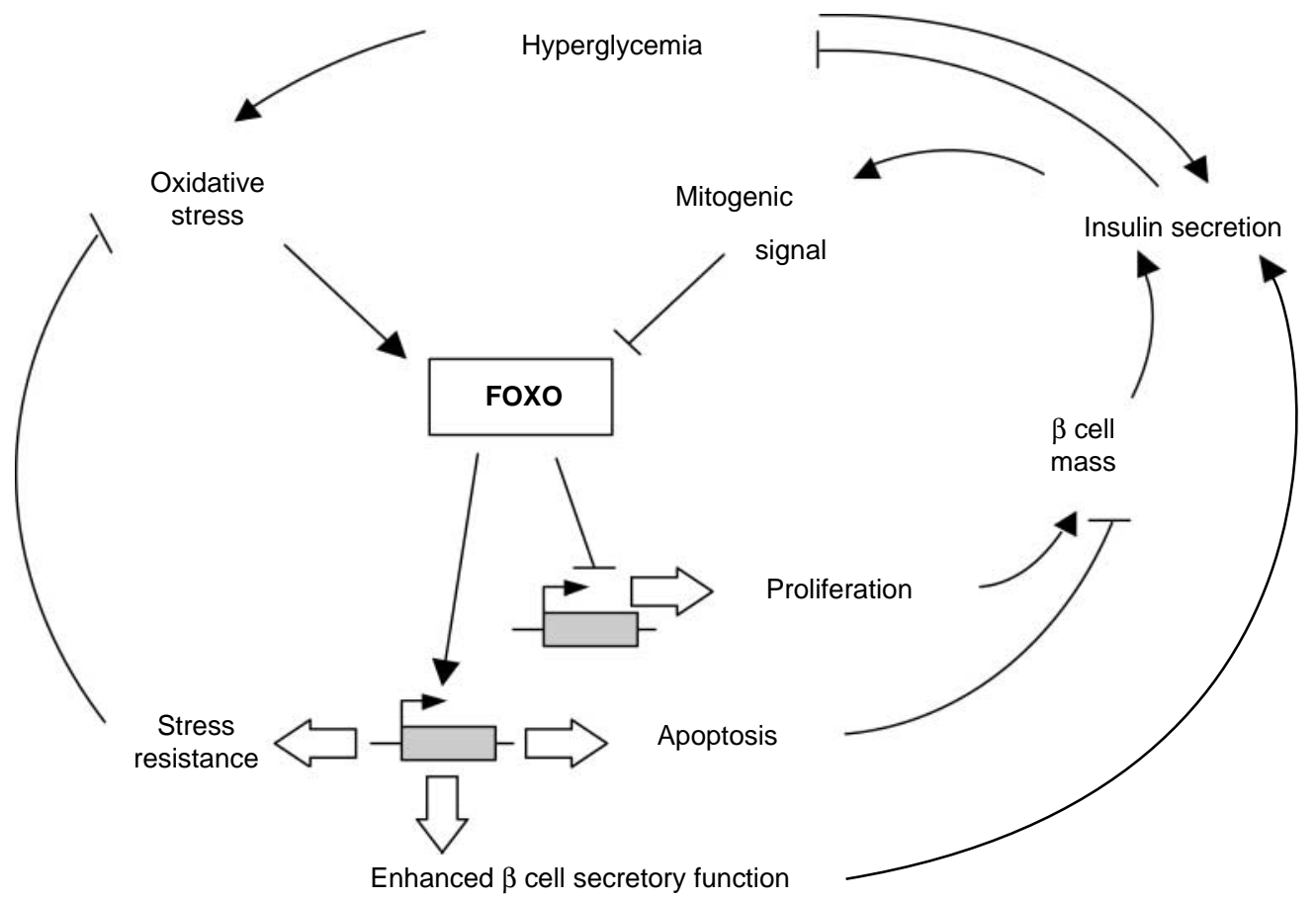

Figure $7 \mathrm{FOXO}$ as an integrator of metabolic and hormonal feedback to $\beta$ cell function.

the latter two being used when the disease is accompanied by drastic reduction in $\beta$ cell function and/or mass. An alternative strategy aiming at promoting $\beta$ cell growth, possibly by acting on the Akt-FOXO pathway, could be envisioned. Note that the systemic administration of drugs addressing the FOXO pathway might favor tumorigenesis and increase the risk of cancer. Therefore, drugs acting on FOXO would be more safely applied ex vivo, for example, to improve the success of islet transplantation. In fact, islet transplantation being limited by the availability and viability of isolated islets, promoting $\beta$ cell survival, or expanding the $\beta$ cell population in isolated human islets ex vivo before transplantation with FOXO-targeting drugs - or even FOXO-based gene therapy - could be an interesting option.

\section{Conclusions}

Investigations in model organisms from worm to mice have highlighted the versatility of FOXO factor regulation and the plethora of cellular processes they control. FOXO factors integrate multiple intracellular and extracellular signals. Sensing the balance between growth-promoting extracellular signals and intracellular stress signals, FOXO factors orchestrate the appropriate cellular responses, i.e. either cell growth and resistance to stress or apoptosis. Findings in pancreatic $\beta$ cells are in line with this general model: FOXO responds to stimuli that are physiologically relevant for the endocrine pancreas, such as insulin, glucose, or GLP-1, and FOXO factors control $\beta$ cell growth and physiology. As a key 'node' in the regulatory networks controlling the pancreatic $\beta$ cell, FOXO represents an interesting potential target to develop novel therapeutic approaches for diabetes.

\section{Funding}

Financial support was from Swiss National Foundation, grants no. 3100A0-102147/1 to W Schlegel, and from the Fondation pour Recherches Médicales, Geneva. The authors declare that there is no conflict of interest that would prejudice the impartiality of the present work.

\section{References}

Altomonte J, Cong L, Harbaran S, Richter A, Xu J, Meseck M \& Dong HH 2004 Foxo1 mediates insulin action on apoC-III and triglyceride metabolism. Journal of Clinical Investigation 114 1493-1503.

Bakker WJ, Blazquez-Domingo M, Kolbus A, Besooyen J, Steinlein P, Beug H, Coffer PJ, Lowenberg B, von Lindern M \& van Dijk TB 2004 FoxO3a regulates erythroid differentiation and induces BTG1, an activator of protein arginine methyl transferase 1. Journal of Cell Biology 164 175-184.

Barthel A, Schmoll D, Kruger KD, Roth RA \& Joost HG 2002 Regulation of the forkhead transcription factor FKHR (FOXO1a) by glucose starvation and AICAR, an activator of AMP-activated protein kinase. Endocrinology 143 3183-3186.

Barthel A, Schmoll D \& Unterman TG 2005 FoxO proteins in insulin action and metabolism. Trends in Endocrinology and Metabolism 16 183-189.

Baumeister R, Schaffitzel E \& Hertweck M 2006 Endocrine signaling in Caenorhabditis elegans controls stress response and longevity. Journal of Endocrinology 190 191-202. 
Biggs WH 3rd, Meisenhelder J, Hunter T, Cavenee WK \& Arden KC 1999 Protein kinase B/Akt-mediated phosphorylation promotes nuclear exclusion of the winged helix transcription factor FKHR 1. PNAS 96 7421-7426.

Bluher M, Kahn BB \& Kahn CR 2003 Extended longevity in mice lacking the insulin receptor in adipose tissue. Science 299 572-574.

Borkhardt A, Repp R, Haas OA, Leis T, Harbott J, Kreuder J, Hammermann J, Henn T \& Lampert F 1997 Cloning and characterization of AFX, the gene that fuses to MLL in acute leukemias with a $\mathrm{t}(\mathrm{X} ; 11)(\mathrm{q} 13 ; \mathrm{q} 23)$. Oncogene 14 195-202.

Brunet A, Bonni A, Zigmond MJ, Lin MZ, Juo P, Hu LS, Anderson MJ, Arden KC, Blenis J \& Greenberg ME 1999 Akt promotes cell survival by phosphorylating and inhibiting a Forkhead transcription factor. Cell 96 857-868.

Brunet A, Park J, Tran H, Hu LS, Hemmings BA \& Greenberg ME 2001 Protein kinase SGK mediates survival signals by phosphorylating the forkhead transcription factor FKHRL1 (FOXO3a). Molecular and Cellular Biology 21 952-965.

Brunet A, Sweeney LB, Sturgill JF, Chua KF, Greer PL, Lin Y, Tran H, Ross SE, Mostoslavsky R, Cohen HY et al. 2004 Stress-dependent regulation of FOXO transcription factors by the SIRT1 deacetylase. Science 303 2011-2015.

Buteau J, Foisy S, Joly E \& Prentki M 2003 Glucagon-like peptide 1 induces pancreatic beta-cell proliferation via transactivation of the epidermal growth factor receptor. Diabetes 52 124-132.

Buteau J, Spatz ML \& Accili D 2006 Transcription factor FoxO1 mediates glucagon-like peptide-1 effects on pancreatic beta-cell mass. Diabetes $\mathbf{5 5}$ 1190-1196.

Castrillon DH, Miao L, Kollipara R, Horner JW \& DePinho RA 2003 Suppression of ovarian follicle activation in mice by the transcription factor Foxo3a. Science 301 215-218.

Chan HM \& La Thangue NB 2001 p300/CBP proteins: HATs for transcriptional bridges and scaffolds. Journal of Cell Science 114 2363-2373.

Charvet C, Alberti I, Luciano F, Jacquel A, Bernard A, Auberger P \& Deckert M 2003 Proteolytic regulation of Forkhead transcription factor FOXO3a by caspase-3-like proteases. Oncogene 22 4557-4568.

Contreras JL, Smyth CA, Bilbao G, Young CJ, Thompson JA \& Eckhoff DE 2002 Simvastatin induces activation of the serine-threonine protein kinase AKT and increases survival of isolated human pancreatic islets. Transplantation 74 1063-1069.

Cunningham MA, Zhu Q, Unterman TG \& Hammond JM 2003 Folliclestimulating hormone promotes nuclear exclusion of the forkhead transcription factor FoxO1a via phosphatidylinositol 3-kinase in porcine granulosa cells. Endocrinology 144 5585-5594.

Cunningham MA, Zhu Q \& Hammond JM 2004 FoxO1a can alter cell cycle progression by regulating the nuclear localization of p27kip in granulosa cells. Molecular Endocrinology 18 1756-1767.

Daly C, Wong V, Burova E, Wei Y, Zabski S, Griffiths J, Lai KM, Lin HC, Ioffe E, Yancopoulos GD et al. 2004 Angiopoietin-1 modulates endothelial cell function and gene expression via the transcription factor FKHR (FOXO1). Genes and Development 18 1060-1071.

Del Guerra S, Lupi R, Marselli L, Masini M, Bugliani M, Sbrana S, Torri S, Pollera M, Boggi U, Mosca F et al. 2005 Functional and molecular defects of pancreatic islets in human type 2 diabetes. Diabetes $\mathbf{5 4}$ 727-735.

Dickson LM \& Rhodes CJ 2004 Pancreatic beta-cell growth and survival in the onset of type 2 diabetes: a role for protein kinase B in the Akt? American Journal of Physiology, Endocrinology and Metabolism 287 E192-E198.

Dijkers PF, Medema RH, Lammers JW, Koenderman L \& Coffer PJ 2000 Expression of the pro-apoptotic Bcl-2 family member Bim is regulated by the forkhead transcription factor FKHR-L1. Current Biology 10 1201-1204.

Dowell P, Otto TC, Adi S \& Lane MD 2003 Convergence of peroxisome proliferator-activated receptor gamma and Foxo1 signaling pathways. Journal of Biological Chemistry 278 45485-45491.

Essers MA, Weijzen S, de Vries-Smits AM, Saarloos I, de Ruiter ND, Bos JL \& Burgering BM 2004 FOXO transcription factor activation by oxidative stress mediated by the small GTPase Ral and JNK. EMBO Journal 23 4802-4812.

Essers MA, de Vries-Smits LM, Barker N, Polderman PE, Burgering BM \& Korswagen HC 2005 Functional interaction between beta-catenin and FOXO in oxidative stress signaling. Science 308 1181-1184.
Fukuoka M, Daitoku H, Hatta M, Matsuzaki H, Umemura S \& Fukamizu A 2003 Negative regulation of forkhead transcription factor AFX (Foxo4) by CBPinduced acetylation. International Journal of Molecular Medicine 12 503-508.

Furuyama T, Nakazawa T, Nakano I \& Mori N 2000 Identification of the differential distribution patterns of mRNAs and consensus binding sequences for mouse DAF-16 homologues. Biochemical Journal 349 629-634.

Furuyama T, Yamashita H, Kitayama K, Higami Y, Shimokawa I \& Mori N 2002 Effects of aging and caloric restriction on the gene expression of Foxo1, 3, and 4 (FKHR, FKHRL1, and AFX) in the rat skeletal muscles. Microscopy Research and Technique 59 331-334.

Furuyama T, Kitayama K, Yamashita H \& Mori N 2003 Forkhead transcription factor FOXO1 (FKHR)-dependent induction of PDK4 gene expression in skeletal muscle during energy deprivation. Biochemical Journal 375 365-371.

Furuyama T, Kitayama K, Shimoda Y, Ogawa M, Sone K, Yoshida-Araki K, Hisatsune H, Nishikawa S, Nakayama K, Nakayama K et al. 2004 Abnormal angiogenesis in Foxo1 (Fkhr)-deficient mice. Journal of Biological Chemistry 279 34741-34749.

Galili N, Davis RJ, Fredericks WJ, Mukhopadhyay S, Rauscher FJ 3rd, Emanuel BS, Rovera G \& Barr FG 1993 Fusion of a fork head domain gene to PAX3 in the solid tumour alveolar rhabdomyosarcoma. Nature Genetics $\mathbf{5}$ 230-235.

Georgia S \& Bhushan A 2004 Beta cell replication is the primary mechanism for maintaining postnatal beta cell mass. Journal of Clinical Investigation $\mathbf{1 1 4}$ 963-968.

Giannakou ME, Goss M, Junger MA, Hafen E, Leevers SJ \& Partridge L 2004 Long-lived Drosophila with overexpressed dFOXO in adult fat body. Science 305361.

Glauser DA \& Schlegel W 2006 Mechanisms of transcriptional regulation underlying temporal integration of signals. Nucleic Acids Research 34 5175-5183.

Greer EL \& Brunet A 2005 FOXO transcription factors at the interface between longevity and tumor suppression. Oncogene 24 7410-7425.

Hashimoto N, Kido Y, Uchida T, Asahara S, Shigeyama Y, Matsuda T, Takeda A, Tsuchihashi D, Nishizawa A, Ogawa W et al. 2006 Ablation of PDK1 in pancreatic beta cells induces diabetes as a result of loss of beta cell mass. Nature Genetics 38 589-593.

Hillion J, Le Coniat M, Jonveaux P, Berger R \& Bernard OA 1997 AF6q21, a novel partner of the MLL gene in $\mathrm{t}(6 ; 11)(\mathrm{q} 21 ; \mathrm{q} 23)$, defines a forkhead transcriptional factor subfamily. Blood 90 3714-3719.

Hoekman MF, Jacobs FM, Smidt MP \& Burbach JP 2006 Spatial and temporal expression of FoxO transcription factors in the developing and adult murine brain. Gene Expression Patterns 6 134-140.

Holz GG \& Chepurny OG 2005 Diabetes outfoxed by GLP-1? Sci STKE 2005 pe2.

Holzenberger M, Dupont J, Ducos B, Leneuve P, Geloen A, Even PC, Cervera P \& Le Bouc Y 2003 IGF-1 receptor regulates lifespan and resistance to oxidative stress in mice. Nature 421 182-187.

van der Horst A, Tertoolen LG, de Vries-Smits LM, Frye RA, Medema RH \& Burgering BM 2004 FOXO4 is acetylated upon peroxide stress and deacetylated by the longevity protein hSir2 (SIRT1). Journal of Biological Chemistry $27928873-28879$.

Hosaka T, Biggs WH 3rd, Tieu D, Boyer AD, Varki NM, Cavenee WK \& Arden KC 2004 Disruption of forkhead transcription factor (FOXO) family members in mice reveals their functional diversification. PNAS 101 2975-2980

Hu MC, Lee DF, Xia W, Golfman LS, Ou-Yang F, Yang JY, Zou Y, Bao S, Hanada N, Saso $\mathrm{H}$ et al. 2004 IkappaB kinase promotes tumorigenesis through inhibition of forkhead FOXO3a. Cell 117 225-237.

Huang H, Regan KM, Wang F, Wang D, Smith DI, van Deursen JM \& Tindall DJ 2005 Skp2 inhibits FOXO1 in tumor suppression through ubiquitin-mediated degradation. PNAS 102 1649-1654.

Hwangbo DS, Gershman B, Tu MP, Palmer M \& Tatar M 2004 Drosophila dFOXO controls lifespan and regulates insulin signalling in brain and fat body. Nature $429562-566$.

Kaestner KH, Knochel W \& Martinez DE 2000 Unified nomenclature for the winged helix/forkhead transcription factors. Genes and Development 14 $142-146$. 
Kaneto H, Nakatani Y, Kawamori D, Miyatsuka T, Matsuoka TA, Matsuhisa M \& Yamasaki Y 2005 Role of oxidative stress, endoplasmic reticulum stress, and c-Jun $\mathrm{N}$-terminal kinase in pancreatic beta-cell dysfunction and insulin resistance. International Journal of Biochemistry and Cell Biology 37 1595-1608.

Kawamori D, Kaneto H, Nakatani Y, Matsuoka TA, Matsuhisa M, Hori M \& Yamasaki Y 2006 The forkhead transcription factor Foxo1 bridges the JNK pathway and the transcription factor PDX-1 through its intracellular translocation. Journal of Biological Chemistry 281 1091-1098.

Kim SJ, Winter K, Nian C, Tsuneoka M, Koda Y \& McIntosh CH 2005 Glucose-dependent insulinotropic polypeptide (GIP) stimulation of pancreatic beta-cell survival is dependent upon phosphatidylinositol 3-kinase $(\mathrm{PI} 3 \mathrm{~K})$ / protein kinase $\mathrm{B}(\mathrm{PKB})$ signaling, inactivation of the forkhead transcription factor Foxo1, and down-regulation of bax expression. Journal of Biological Chemistry 280 22297-22307.

Kim MS, Pak YK, Jang PG, Namkoong C, Choi YS, Won JC, Kim KS, Kim SW, Kim HS, Park JY et al. 2006 Role of hypothalamic Foxo1 in the regulation of food intake and energy homeostasis. Nature Neuroscience 9 901-906.

Kitamura T, Nakae J, Kitamura Y, Kido Y, Biggs WH 3rd, Wright CV, White MF, Arden KC \& Accili D 2002 The forkhead transcription factor Foxo1 links insulin signaling to Pdx1 regulation of pancreatic beta cell growth. Journal of Clinical Investigation 110 1839-1847.

Kitamura YI, Kitamura T, Kruse JP, Raum JC, Stein R, Gu W \& Accili D 2005 FoxO1 protects against pancreatic beta cell failure through NeuroD and MafA induction. Cell Metabolism 2 153-163.

Kitamura T, Feng Y, Ido Kitamura Y, Chua SC, Xu AW, Barsh GS, Rossetti L \& Accili D 2006 Forkhead protein FoxO1 mediates Agrp-dependent effects of leptin on food intake. Nature Medicine 12 534-540.

Kops GJ, Dansen TB, Polderman PE, Saarloos I, Wirtz KW, Coffer PJ, Huang TT, Bos JL, Medema RH \& Burgering BM 2002 Forkhead transcription factor FOXO3a protects quiescent cells from oxidative stress. Nature $\mathbf{4 1 9}$ 316-321.

Kushner JA, Ciemerych MA, Sicinska E, Wartschow LM, Teta M, Long SY, Sicinski P \& White MF 2005 Cyclins D2 and D1 are essential for postnatal pancreatic beta-cell growth. Molecular and Cellular Biology 25 3752-3762.

Lehtinen MK, Yuan Z, Boag PR, Yang Y, Villen J, Becker EB, Dibacco S, de la Iglesia N, Gygi S, Blackwell TK et al. 2006 A conserved MSTFOXO signaling pathway mediates oxidative-stress responses and extends life span. Cell 125 987-1001.

Leibiger IB, Leibiger B \& Berggren PO 2002 Insulin feedback action on pancreatic beta-cell function. FEBS Letters $5321-6$.

Li P, Lee H, Guo S, Unterman TG, Jenster G \& Bai W 2003 AKTindependent protection of prostate cancer cells from apoptosis mediated through complex formation between the androgen receptor and FKHR. Molecular and Cellular Biology 23 104-118.

Li L, El-Kholy W, Rhodes CJ \& Brubaker PL 2005 Glucagon-like peptide-1 protects beta cells from cytokine-induced apoptosis and necrosis: role of protein kinase B. Diabetologia 48 1339-1349.

Martinez SC, Cras-Meneur C, Bernal-Mizrachi E \& Permutt MA 2006 Glucose regulates foxo1 through insulin receptor signaling in the pancreatic islet $\beta$-cell. Diabetes 55 1581-1591.

Martinez-Gac L, Marques M, Garcia Z, Campanero MR \& Carrera AC 2004 Control of cyclin G2 mRNA expression by forkhead transcription factors: novel mechanism for cell cycle control by phosphoinositide 3-kinase and forkhead. Molecular and Cellular Biology 24 2181-2189.

Matsumoto M \& Accili D 2005 All roads lead to FoxO. Cell Metabolism $1215-216$

Medema RH, Kops GJ, Bos JL \& Burgering BM 2000 AFX-like Forkhead transcription factors mediate cell-cycle regulation by Ras and PKB through p27kip1. Nature 404 782-787.

Modur V, Nagarajan R, Evers BM \& Milbrandt J 2002 FOXO proteins regulate tumor necrosis factor-related apoptosis inducing ligand expression. Implications for PTEN mutation in prostate cancer. Journal of Biological Chemistry 277 47928-47937.

Motta MC, Divecha N, Lemieux M, Kamel C, Chen D, Gu W, Bultsma Y, McBurney M \& Guarente L 2004 Mammalian SIRT1 represses forkhead transcription factors. Cell 116 551-563.
Moynihan KA, Grimm AA, Plueger MM, Bernal-Mizrachi E, Ford E, CrasMeneur C, Permutt MA \& Imai S 2005 Increased dosage of mammalian Sir2 in pancreatic beta cells enhances glucose-stimulated insulin secretion in mice. Cell Metabolism 2 105-117.

Murphy CT, McCarroll SA, Bargmann CI, Fraser A, Kamath RS, Ahringer J, Li H \& Kenyon C 2003 Genes that act downstream of DAF-16 to influence the lifespan of Caenorhabditis elegans. Nature 424 277-283.

Nakae J, Kitamura T, Silver DL \& Accili D 2001 The forkhead transcription factor Foxo1 (Fkhr) confers insulin sensitivity onto glucose-6-phosphatase expression. Journal of Clinical Investigation 108 1359-1367.

Nakae J, Kitamura T, Kitamura Y, Biggs WH 3rd, Arden KC \& Accili D 2003 The forkhead transcription factor Foxo1 regulates adipocyte differentiation. Developmental Cell 4 119-129.

Nemoto S \& Finkel T 2002 Redox regulation of forkhead proteins through a p66shc-dependent signaling pathway. Science 295 2450-2452.

Ohsugi M, Cras-Meneur C, Zhou Y, Bernal-Mizrachi E, Johnson JD, Luciani DS, Polonsky KS \& Permutt MA 2005 Reduced expression of the insulin receptor in mouse insulinoma (MIN6) cells reveals multiple roles of insulin signaling in gene expression, proliferation, insulin content, and secretion. Journal of Biological Chemistry 280 4992-5003.

Okamoto H, Hribal ML, Lin HV, Bennett WR, Ward A \& Accili D 2006 Role of the forkhead protein FoxO1 in beta cell compensation to insulin resistance. Journal of Clinical Investigation 116 775-782.

Park Y, Maizels ET, Feiger ZJ, Alam H, Peters CA, WoodruffTK, Unterman TG, Lee EJ, Jameson JL \& Hunzicker-Dunn M 2005 Induction of cyclin D2 in rat granulosa cells requires FSH-dependent relief from FOXO1 repression coupled with positive signals from Smad. Journal of Biological Chemistry 280 9135-9148.

Parry P, Wei Y \& Evans G 1994 Cloning and characterization of the $t(X ; 11)$ breakpoint from a leukemic cell line identify a new member of the forkhead gene family. Genes Chromosomes and Cancer 11 79-84.

Perrot V \& Rechler MM 2003 Characterization of insulin inhibition of transactivation by a C-terminal fragment of the forkhead transcription factor Foxo1 in rat hepatoma cells. Journal of Biological Chemistry 278 26111-26119.

Pohl BS, Schon C, Rossner A \& Knochel W 2004 The FoxO-subclass in Xenopus laevis development. Gene Expression Patterns 5 187-192.

Potente M, Urbich C, Sasaki K, Hofmann WK, Heeschen C, Aicher A, Kollipara R, DePinho RA, Zeiher AM \& Dimmeler S 2005 Involvement of Foxo transcription factors in angiogenesis and postnatal neovascularization. Journal of Clinical Investigation 115 2382-2392.

Puigserver P, Rhee J, Donovan J, Walkey CJ, Yoon JC, Oriente F, Kitamura Y, Altomonte J, Dong H, Accili D et al. 2003 Insulin-regulated hepatic gluconeogenesis through FOXO1-PGC-1alpha interaction. Nature $\mathbf{4 2 3}$ 550-555.

Ramaswamy S, Nakamura N, Sansal I, Bergeron L \& Sellers WRA 2002 A novel mechanism of gene regulation and tumor suppression by the transcription factor FKHR. Cancer Cell 2 81-91.

Reddy P, Shen L, Ren C, Boman K, Lundin E, Ottander U, Lindgren P, Liu YX, Sun QY \& Liu K 2005 Activation of Akt (PKB) and suppression of FKHRL1 in mouse and rat oocytes by stem cell factor during follicular activation and development. Developmental Biology 281 160-170.

Rena G, Woods YL, Prescott AR, Peggie M, Unterman TG, Williams MR \& Cohen P 2002 Two novel phosphorylation sites on FKHR that are critical for its nuclear exclusion. EMBO Journal 21 2263-2271.

Rhodes CJ 2005 Type 2 diabetes - a matter of beta-cell life and death? Science 307 380-384.

Richards JS, Sharma SC, Falender AE \& Lo YH 2002 Expression of FKHR, FKHRL1, and $A F X$ genes in the rodent ovary: evidence for regulation by IGF-I, estrogen, and the gonadotropins. Molecular Endocrinology 16 580-599.

Rogina B \& Helfand SL 2004 Sir2 mediates longevity in the fly through a pathway related to calorie restriction. PNAS 101 15998-16003.

Rutter GA, Da Silva Xavier G \& Leclerc I 2003 Roles of 5'-AMP-activated protein kinase (AMPK) in mammalian glucose homoeostasis. Biochemical Journal 375 1-16. 
Sandri M, Sandri C, Gilbert A, Skurk C, Calabria E, Picard A, Walsh K, Schiaffino S, Lecker SH \& Goldberg AL 2004 Foxo transcription factors induce the atrophy-related ubiquitin ligase atrogin-1 and cause skeletal muscle atrophy. Cell 117 399-412.

Seoane J, Le HV, Shen L, Anderson SA \& Massague J 2004 Integration of Smad and forkhead pathways in the control of neuroepithelial and glioblastoma cell proliferation. Cell 117 211-223.

Srinivasan S, Bernal-Mizrachi E, Ohsugi M \& Permutt MA 2002 Glucose promotes pancreatic islet beta-cell survival through a PI 3-kinase/Aktsignaling pathway. American Journal of Physiology, Endocrinology and Metabolism 283 E784-E793.

Tissenbaum HA \& Guarente L 2001 Increased dosage of a sir-2 gene extends lifespan in Caenorhabditis elegans. Nature 410 227-230.

Tran H, Brunet A, Grenier JM, Datta SR, Fornace AJ Jr, DiStefano PS, Chiang LW \& Greenberg ME 2002 DNA repair pathway stimulated by the forkhead transcription factor FOXO3a through the Gadd45 protein. Science 296 530-534.

Trumper K, Trumper A, Trusheim H, Arnold R, Goke B \& Horsch D 2000 Integrative mitogenic role of protein kinase B/Akt in beta-cells. Annals of the New York Academy of Sciences 921 242-250.

Trumper A, Trumper K, Trusheim H, Arnold R, Goke B \& Horsch D 2001 Glucose-dependent insulinotropic polypeptide is a growth factor for beta (INS-1) cells by pleiotropic signaling. Molecular Endocrinology 15 1559-1570.

Tsai WC, Bhattacharyya N, Han LY, Hanover JA \& Rechler MM 2003 Insulin inhibition of transcription stimulated by the forkhead protein Foxo1 is not solely due to nuclear exclusion. Endocrinology 144 5615-5622.
Vogt PK, Jiang H \& Aoki M 2005 Triple layer control: phosphorylation, acetylation and ubiquitination of FOXO proteins. Cell Cycle 4 908-913.

Wang Q, Li L, Xu E, Wong V, Rhodes C \& Brubaker PL 2004 Glucagon-like peptide-1 regulates proliferation and apoptosis via activation of protein kinase B in pancreatic INS-1 beta cells. Diabetologia 47 478-487.

Wang MC, Bohmann D \& Jasper H 2005 JNK extends life span and limits growth by antagonizing cellular and organism-wide responses to insulin signaling. Cell 121 115-125.

Wessells RJ, Fitzgerald E, Cypser JR, Tatar M \& Bodmer R 2004 Insulin regulation of heart function in aging fruit flies. Nature Genetics 36 1275-1281.

Wrede CE, Dickson LM, Lingohr MK, Briaud I \& Rhodes CJ 2002 Protein kinase $\mathrm{B} /$ Akt prevents fatty acid-induced apoptosis in pancreatic beta-cells (INS-1). Journal of Biological Chemistry 277 49676-49684.

Yang H, Zhao R, Yang HY \& Lee MH 2005 Constitutively active FOXO4 inhibits Akt activity, regulates p27 Kip1 stability, and suppresses HER2mediated tumorigenicity. Oncogene 24 1924-1935.

Received in final form 28 November 2006

Accepted 26 December 2006

Made available online as an Accepted Preprint

24 January 2007 